\title{
Structural Modeling of Relationship Among Ethical Climate, Emotional Exhaustion with Job Satisfaction and Turnover Intention
}

\author{
Zahra Lotfi $^{1 *(D)}$, Mohammad Hassani ${ }^{\text {iD }}$, Mahdi Najjari ${ }^{3}$ it
}

1. Master Student, Department of Educational Sciences, Faculty of Basic Sciences, Urmia Branch, Islamic Azad University, Urmia, Iran

2. Professor, Department of Educational Sciences, Faculty of Literature and Humanities, Urmia University, Urmia, Iran

3. PhD Student, Department of Educational Management, Faculty of Literature and Humanities, Urmia University, Urmia, Iran

\begin{tabular}{|c|c|}
\hline Article Info & ABSTRACT \\
\hline $\begin{array}{l}\text { Received: 2020/12/19; } \\
\text { Accepted: 2021/08/07; } \\
\text { ePublished: 2021/09/21 }\end{array}$ & $\begin{array}{l}\text { Background and Objectives: Ethical atmosphere and burnout of employees is } \\
\text { an important issue for the management of the organization and management should } \\
\text { play a key role in improving the performance of employees and the organization. The } \\
\text { present study aimed to model the structural relationship between ethical atmosphere }\end{array}$ \\
\hline do) $10.30699 /$ jergon.9.2.82 & and emotional exhaustion with job satisfaction and turnover intention. \\
\hline
\end{tabular}

Use your device to scan and read the article online

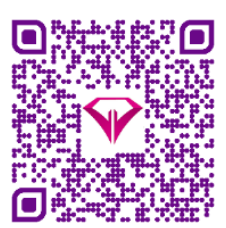

Corresponding Author

\section{Zahra Lotfi}

Master Student, Department of Educational Sciences, Faculty of Basic Sciences, Urmia Branch, Islamic Azad University, Urmia, Iran

Email:

zahralotfi73@yahoo.com
Methods: The present study is applied research in terms of purpose and descriptive-correlational in terms of data collection method. The statistical population includes 125 employees of the West Azerbaijan Gas Company who were surveyed by census method. The data collection tool was a questionnaire. Confirmatory factor analysis and Cronbach's alpha method were used to evaluate the validity and reliability of measuring instruments. Structural equation modeling using Smart PLS software was done to analyze the data.

Results: The results of the determined coefficients showed that the ethical atmosphere was able to explain more than $22 \%$ of the changes in emotional exhaustion. Also, emotional exhaustion can explain more than $44 \%$ of the changes in job satisfaction and $18 \%$ of the changes in the desire to leave the job. The coefficient of morale's impact on job satisfaction with emotional exhaustion was also 0.07 . And the impact coefficient of the ethical atmosphere on the desire to leave the job with an emotional exhaustion was also -0.09 .

Conclusion: Improving the ethical atmosphere of the organization and reducing the emotional burnout of employees leads to job satisfaction and commitment of employees, and as a result, the performance of employees and the organization improves.

Keywords: Ethical Atmosphere, Emotional Exhaustion, Job Satisfaction, Turnover Intention

Copyright (C) 2021, This is an original open-access article distributed under the terms of the Creative Commons Attribution-noncommercial 4.0 International License which permits copy and redistribute of the material just in noncommercial usages with proper citation.

How to Cite This Article:

Lotfi Z, Hassani M, Najjari M. Structural Modeling of Relationship Among Ethical Climate, Emotional Exhaustion with Job Satisfaction and Turnover Intention. Iran J Ergon. 2021; 9(2):82-94 


\section{Extended Abstract}

\section{Introduction}

Ethical atmosphere and burnout of employees is an important issue for the management of the organization and management should play a key role in improving the performance of employees and the organization. The present study aimed to model the structural relationship between ethical atmosphere and emotional exhaustion with job satisfaction and turnover intention.

\section{Methods}

The present study is applied research in terms of purpose and descriptive-correlational in terms of data collection method. The statistical population includes 125 employees of the West Azerbaijan Gas Company who were surveyed by census method. The data collection tool was a questionnaire. Confirmatory factor analysis and Cronbach's alpha method were used to evaluate the validity and reliability of measuring instruments. Structural equation modeling using Smart PLS software was done to analyze the data.

\section{Results}

The results of the determined coefficients showed that the ethical atmosphere was able to explain more than $22 \%$ of the changes in emotional exhaustion. Also, emotional exhaustion can explain more than $44 \%$ of the changes in job satisfaction and $18 \%$ of the changes in the desire to leave the job. The coefficient of morale's impact on job satisfaction with emotional exhaustion was also 0.07. And the impact coefficient of the ethical atmosphere on the desire to leave the job with an emotional exhaustion was also -0.09.

\section{Discussion}

The aim of this study was to structurally model the relationship between ethical atmosphere and emotional burnout with job satisfaction and the tendency to leave the job. According to the test results, the value of multiple correlation coefficient of ethical atmosphere and job satisfaction is equal to 0.577 , which indicates the existence of a direct correlation between these two variables. The results of path coefficients showed that the value of t-statistic in the relationship between ethical atmosphere and job satisfaction was equal to 7.403 , which is significant at $99 \%$ confidence level. Therefore, improving the ethical atmosphere leads to job satisfaction of employees. This finding is consistent with the results of research by Borhani et al. and Nowamka et al. [15, 18]. According to the test results, the value of multiple correlation coefficient of ethical atmosphere with job satisfaction mediated by emotional burnout is equal to 0.08 , which indicates the existence of a direct correlation between these variables. The results of path coefficients showed that the value of $\mathrm{t}$-statistic in the relationship between ethical atmosphere and job satisfaction with the mediation of emotional burnout was equal to 11 , which is significant at $99 \%$ confidence level. Therefore, it can be said that the relationship between ethical atmosphere and job satisfaction is mediated by emotional burnout. This finding was consistent with the results of Nadi and Hazqi [11] and Nawamka et al. The results also showed that the coefficient of multiple correlation of ethical atmosphere and the tendency to leave the job is equal to 0.289 , which indicates the existence of an inverse correlation between these two variables. The results of path coefficients showed that the value of tstatistic in the relationship between ethical atmosphere and job satisfaction was equal to 2.362 , which is significant at $95 \%$ confidence level. On this basis, it can be said that as the ethical atmosphere improves, the tendency to leave the job decreases and vice versa. The results of this study are consistent with the research of Corley [26] and Rahimnia et al. [27]. On the other hand, the results showed that the coefficient of multiple correlation of the moral atmosphere with the tendency to leave the job mediated by emotional burnout is equal to -0.1 , which indicates the inverse correlation between the tendency to leave the job with the mediation of emotional burnout. The ethical atmosphere is reduced by the mediation of emotional exhaustion. The results of path coefficients showed that the value of t-statistic in the relationship between ethical atmosphere and the tendency to leave the job 
mediated by emotional burnout was equal to 12.21 , which is significant at $99 \%$ confidence level. This finding is consistent with the findings of Corley [26] and Rahimnia et al. [27]. Based on the test results, the coefficient of multiple correlations between emotional burnout and job satisfaction is -0.161 , which indicates the existence of an inverse correlation between these two variables, so that with increasing emotional burnout, job satisfaction decreases; on the contrary, the results of path coefficients showed that the value of t-statistic in the relationship between the ethical atmosphere and job satisfaction was equal to 1.668 , which is significant at the level of $90 \%$ confidence. This finding is consistent with the results of the research of Acikgoz and Gunsel [19]. On the other hand, the results of this study showed that the value of multiple correlation coefficient of emotional burnout and tendency to leave the job is equal to 0.204 , which indicates the existence of a direct correlation between these two variables. The results of path coefficients showed that the value of $t$ statistic in the relationship between emotional exhaustion and the tendency to leave the job was equal to 1.788 , which is significant at the level of $90 \%$ confidence. Therefore, it can be said that with the increase in the rate of emotional burnout of employees, the tendency to leave the job also increases. The results of this study are consistent with Javadian and Golparvar research [16].
According to the results, the value of multiple correlation coefficient $(R)$ of ethical atmosphere and emotional burnout is equal to -0.47 , which indicates the existence of an inverse correlation between these two variables. The results of path coefficients showed that the value of $t$-statistic in the relationship between ethical atmos-phere and emotional burnout was equal to 6.831 which is significant at $99 \%$ confidence level. Therefore, it can be said that with the increase of ethical atmosphere, emotional exhaustion decreases and vice versa. This finding is consistent with the results of research by Mulki et $a l$. [9]. Also, They endorsed the positive effect of the ethical atmos-phere on the decrease of emotional burn out of the employees.

\section{Conclusion}

Improving the ethical atmosphere of the organization and reducing the emotional burnout of employees leads to job satisfaction and commitment of employees, and as a result, the performance of employees and the organization improves.

\section{Acknowledgement}

The authors would like to thank all those who helped them in this research.

\section{Conflict of Interest}

The authors declared no conflict of interest. 


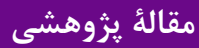

\section{مدل يابى ساختارى ارتباط جو اخلاقى و فرسودگى هيجانى با رضايت شغلى و تمايل به ترك شغل}

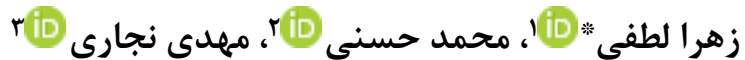

$$
\begin{aligned}
& \text { '. دانشجوى كارشناسى ارشد، كروه علوم تربيتى، دانشكدة علوم بايه، دانشكاه آزاد اسلامى اروميه، اروميه، ايران }
\end{aligned}
$$

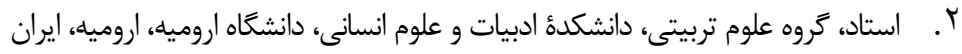

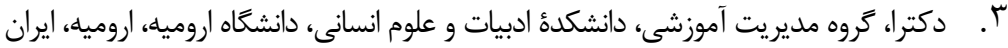

\begin{tabular}{|c|c|}
\hline خلاصه & اطلاعات مقاله \\
\hline 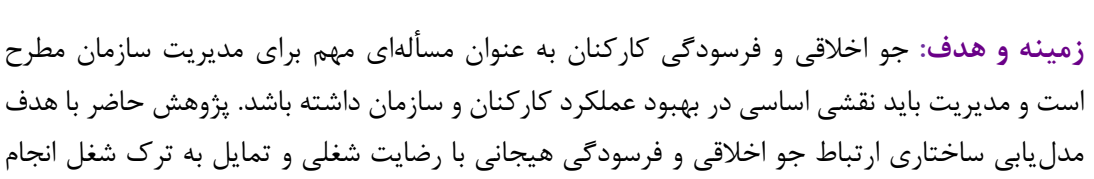 & 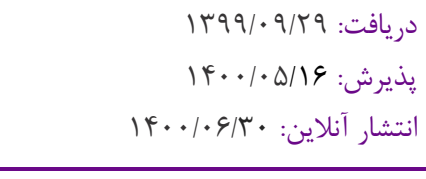 \\
\hline كرفت. & نويسندهُ مسئول: \\
\hline 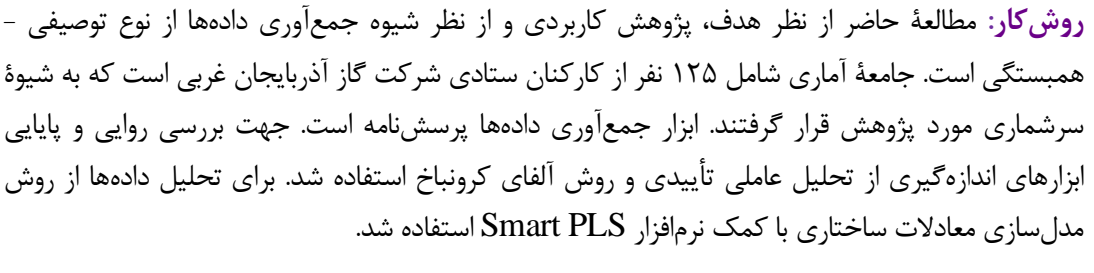 & 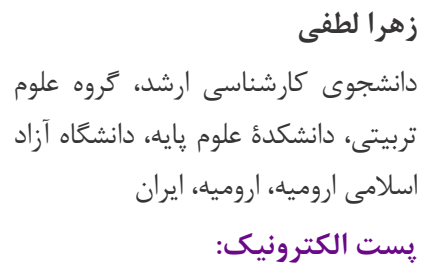 \\
\hline يافتهها: نتايج ضرايب تعيين نشان داد كه جو اخلاقى قادر به تبيين بيش از Y د درصد از تغييرات فرسودىى & zahralotfi73@yahoo.com \\
\hline 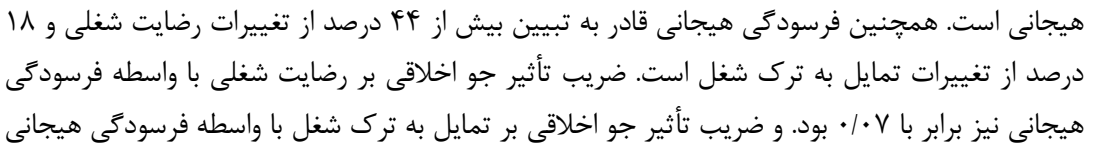 & زبر راى دانلود اين مقاله، كد بد بايل خود اسكن \\
\hline نتيز برابر با 9 • ••- بود. & 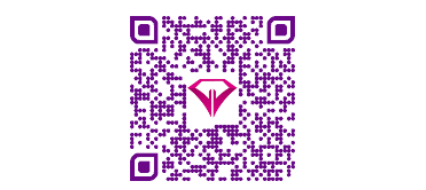 \\
\hline كليدوازهها: جو اخلاقى، فرسودگى هيجانى، رضايت شغلى، تمايل به ترى شغل & 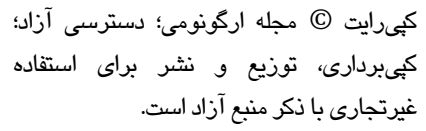 \\
\hline
\end{tabular}

مقد مه

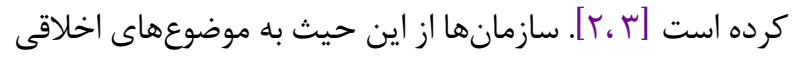

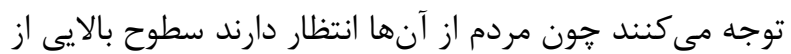
استانداردهاى اخلاقى را نشان دهند. سطوح بالاى استانداردهاى

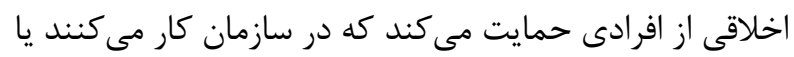

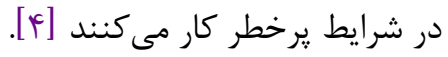
جو اخلاقى شامل الكوهايى است كه رفتار كاركنان را هدايت

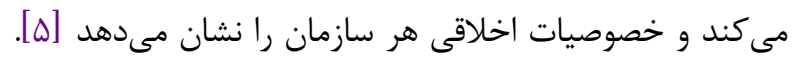
جو اخلاقى را مىتوان به عنوان ادراى عمومى از عملكردهاى

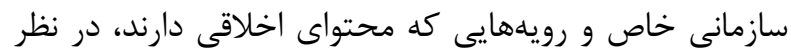

سازمانها براى انجام دادن امور سازمانى خود، علاوه بر معيارهاى سازمانى و قانونى، به مجموعهايى از رهام رهنمودهاى إنى اخلاقى و ارزشى نياز دارند كه آنان را در رفتارها و اعمال ادارى

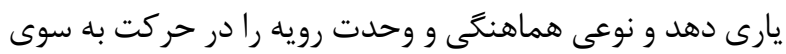

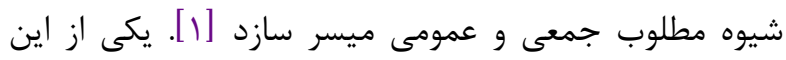
رهنمودهاى اخلاقى و ارزشى كه در سالهاى اخير توجهات

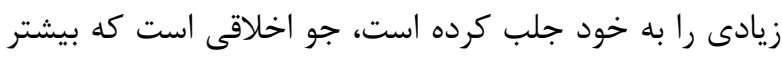

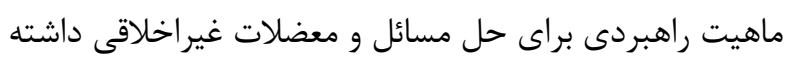
كه طى سال هاى اخير تمامى بشر را به صورت كمابيش تهديد 
شغلى نيز از عوامل مهمم افزايش بهرهورى، دلسوزى كاركنان

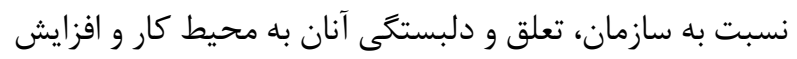

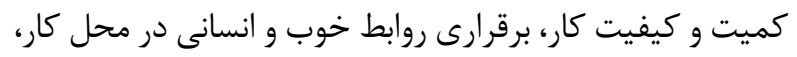

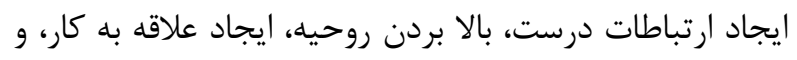

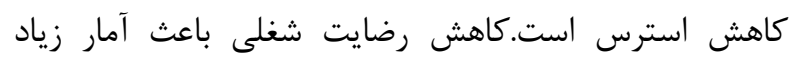

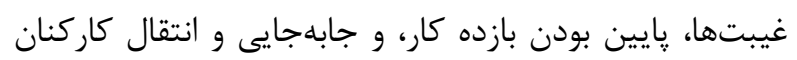

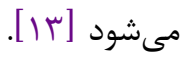

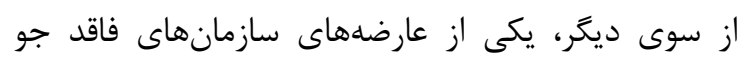

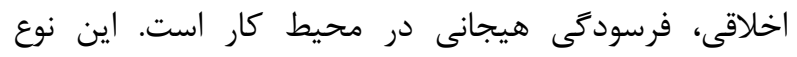

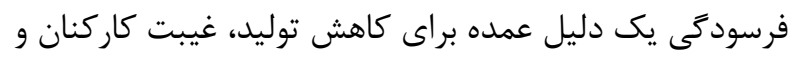

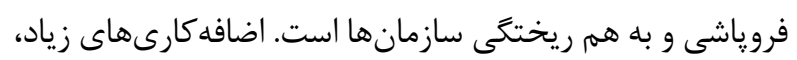

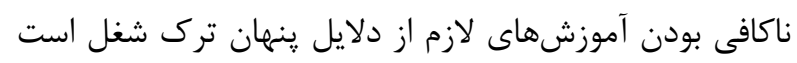

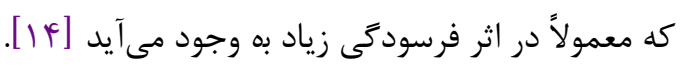
Borhani

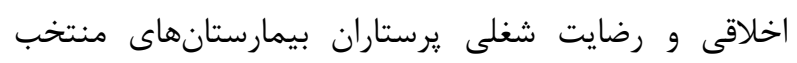

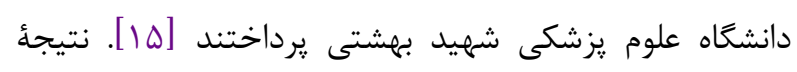

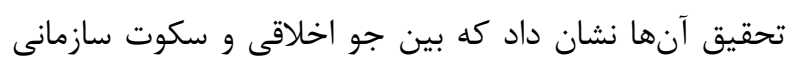

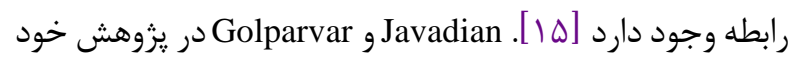
با عنوان بررسى رابطئ استرس شغلى با تركى خدمت و رفتارهاى

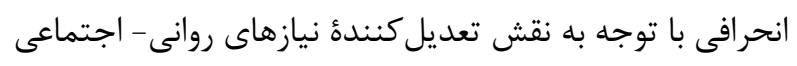

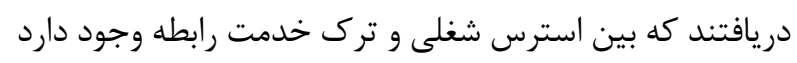

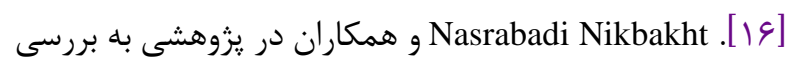

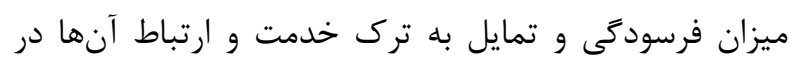

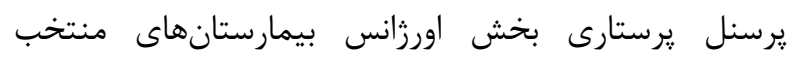

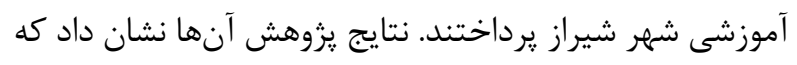

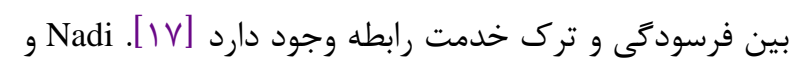
Haziqi

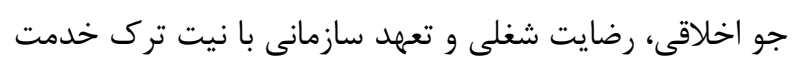

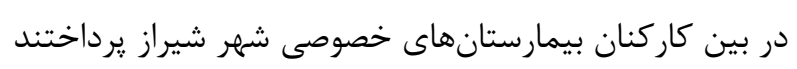

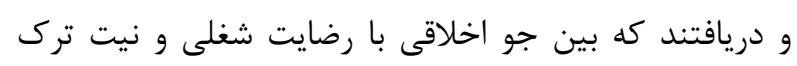

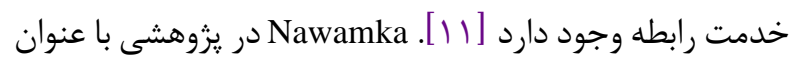
جو اخلاقى و رضايت شغلى در بين خريداران سازمانى نشان داد داد كه جو اخلاقى بر رضايت همكاران از مديران تأثير مثبت داريت دارد

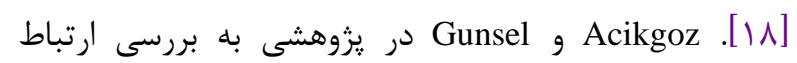

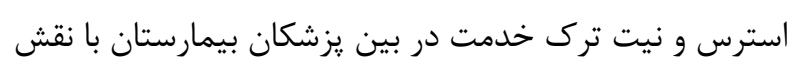

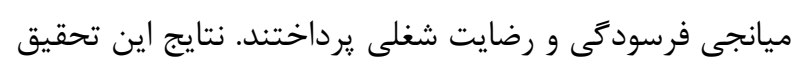

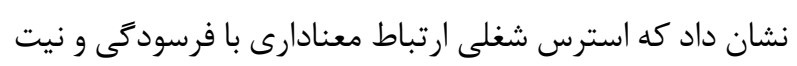

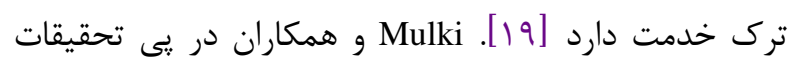

كرفت. افراد در سازمانها دريافتهاند كه هنجارها و قواعد

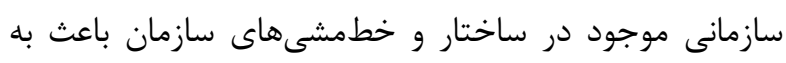

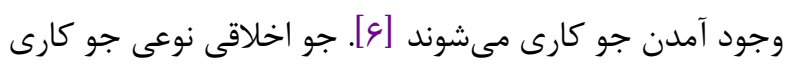

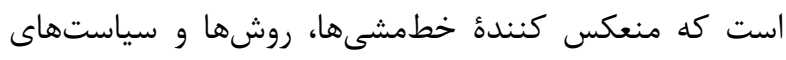

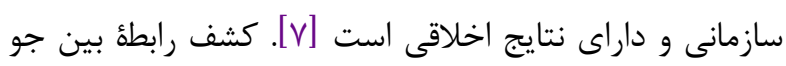

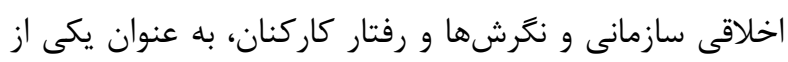

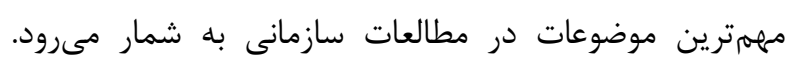

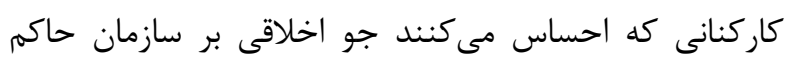

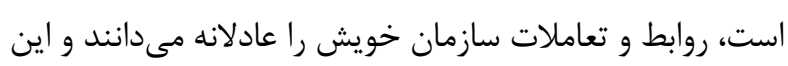

موضوع باعث افزايش رضايت و تعهد كاركنان مىشود [N]. در شرايطى كه كدهاى اخلاقى به وقوع بييوندند، سطوح

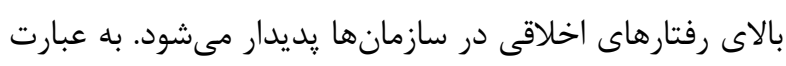

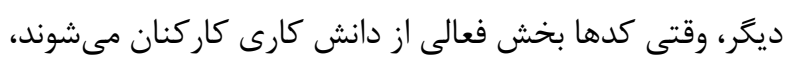

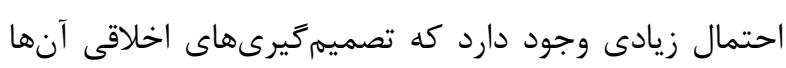

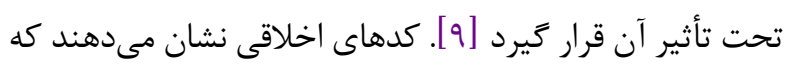

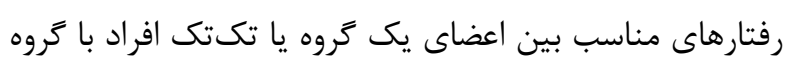

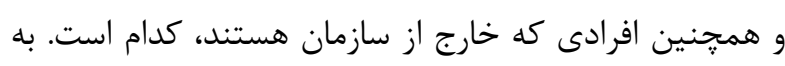

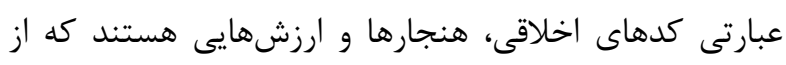

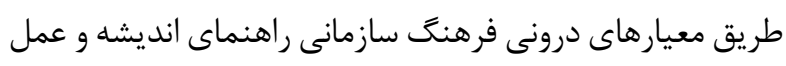

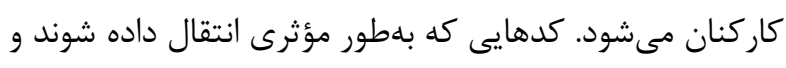

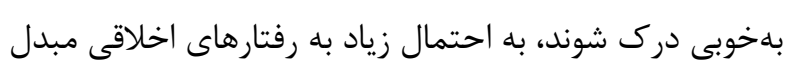

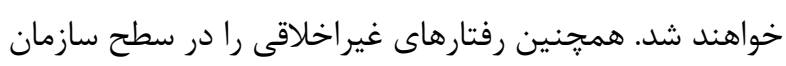

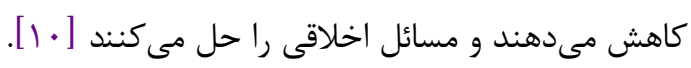

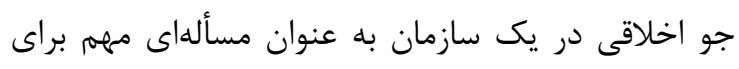

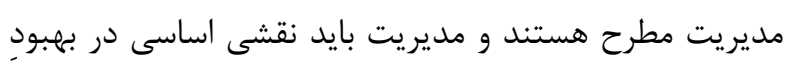

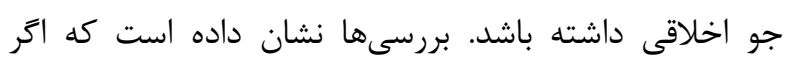

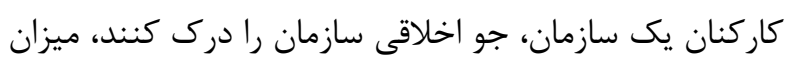

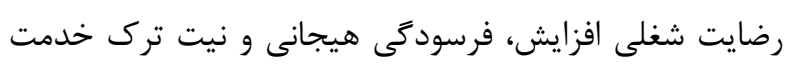

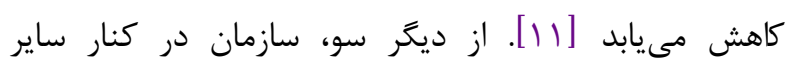

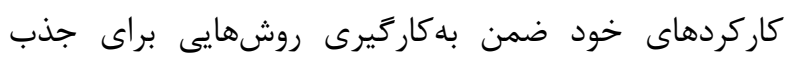

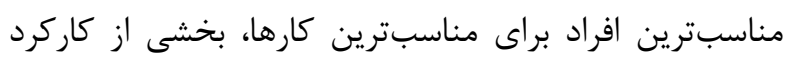

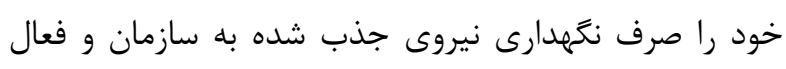

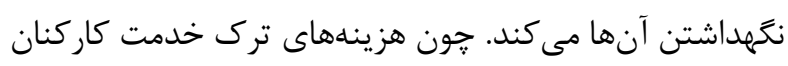

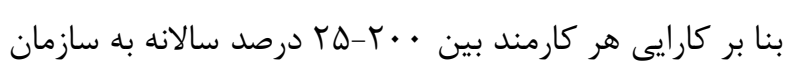

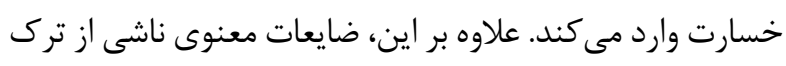

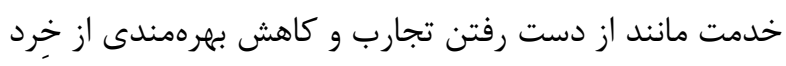

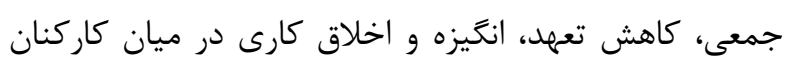

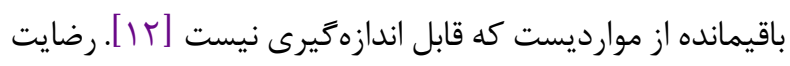


يرسشنامه از طيف ليكرت ينج درجهاى ليكرت (خيلى زياد، زياد،

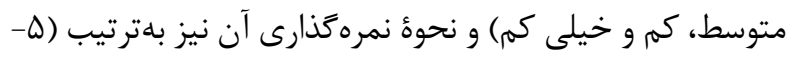
F Golparvar

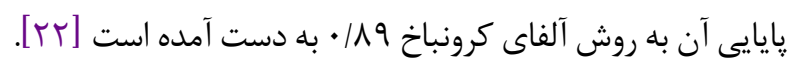

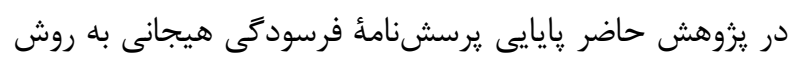

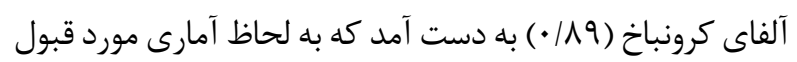

\section{يرسشنامهٔ رضايت شغلى: يرسشنامئ استاندارد Esmiet}

(999 (199، بلمنظور اندازهزيرى رضايت شغلى مورد استفاده قرار

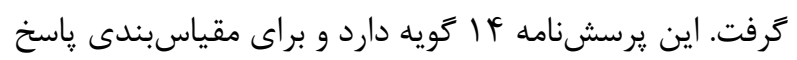

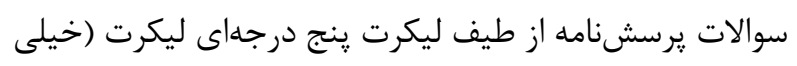

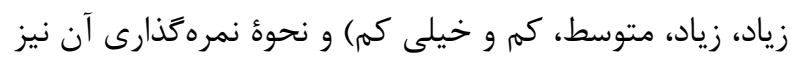

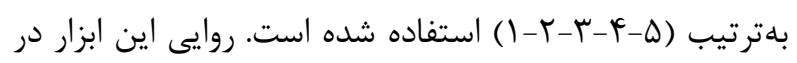

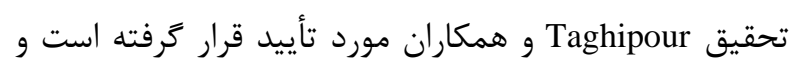

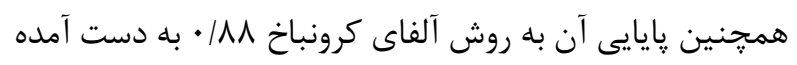

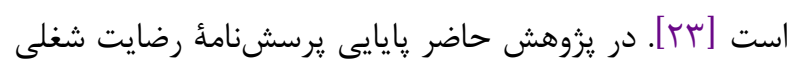

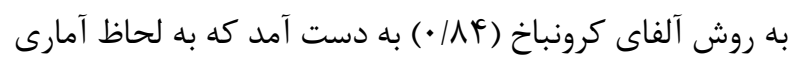
مورد قبول است. يرسشنامهُ تمايل به ترك خدمت: براى بررسى تمايل

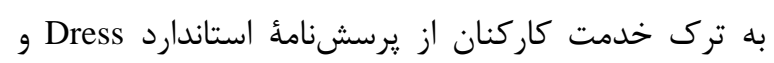
Shaw

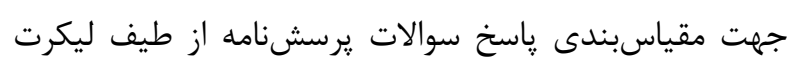

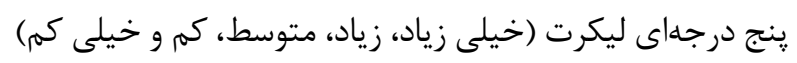

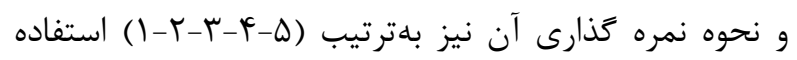

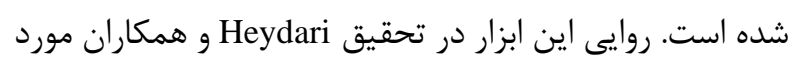

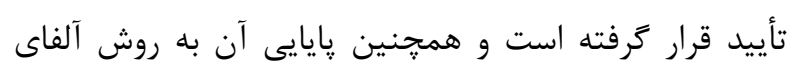

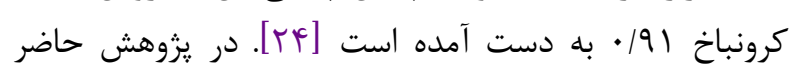

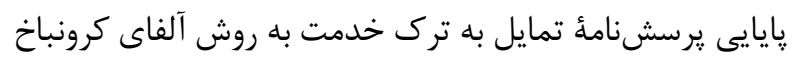
(91/91 ) به دست آمد كه به لحاظ آمارى مورد قبول است.

\section{كافتهها}

براساس شاخصهاى آمار توصيفى نمونه آمارى يزوهش

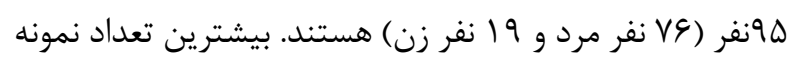

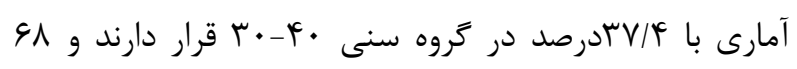
درصد داراى مدرى تحصيلى فوق ليسانس هستند. يس إن از

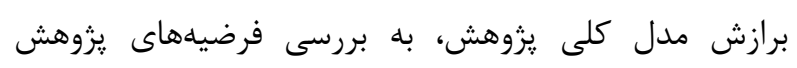

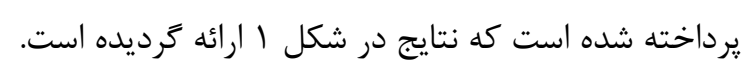

خود به اين نتايج دست يافتند كه جو اخلاقى با رضايت شغلى

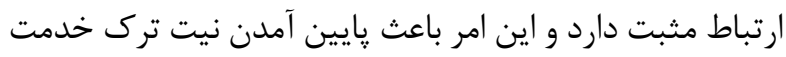

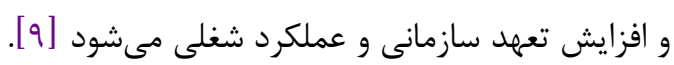

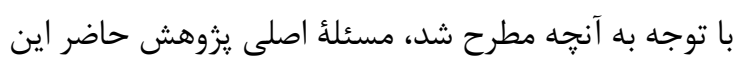

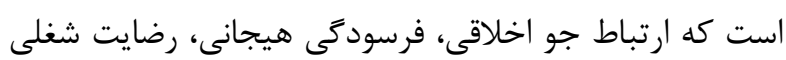

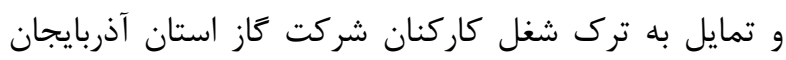
غربى קخكونه است؟

$$
\text { روش كار }
$$

يزوهش حاضر از نظر هدف، كاربردى و از نظر نحوه

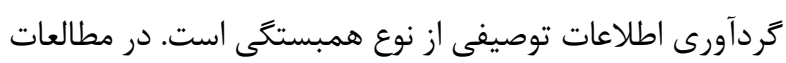

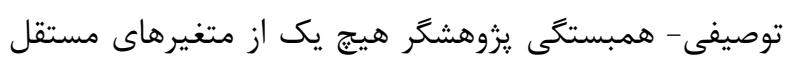

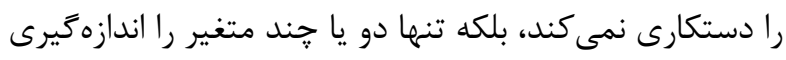

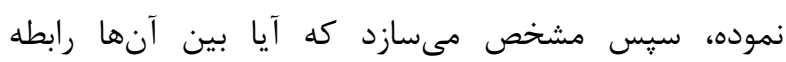

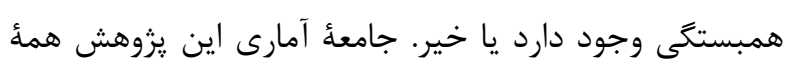

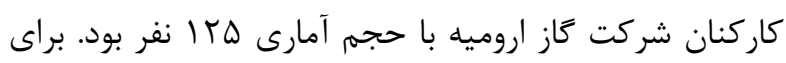

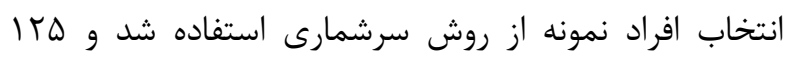

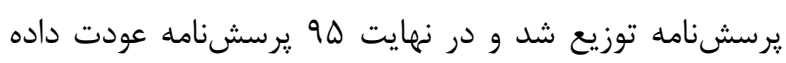

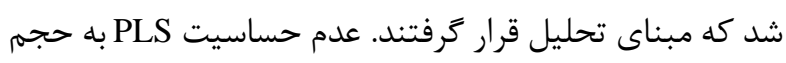

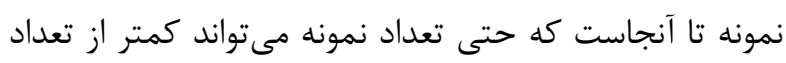
كل متغيرهاى يزوهش باشد [. [ب].

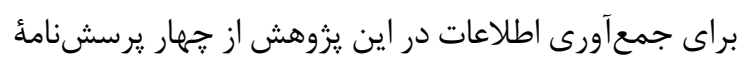
استاندارد استفاده شد.

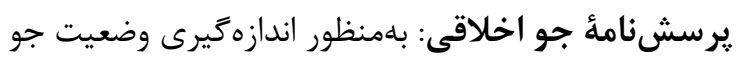

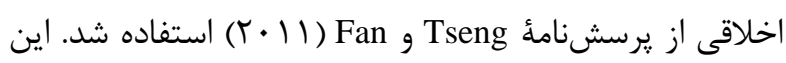

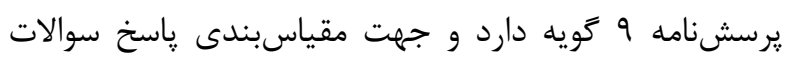

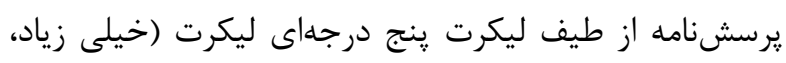

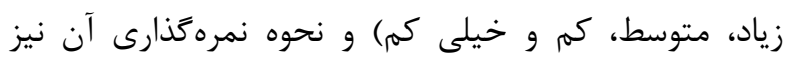

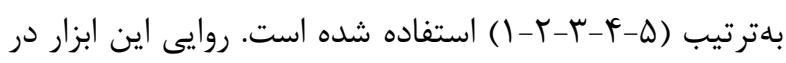

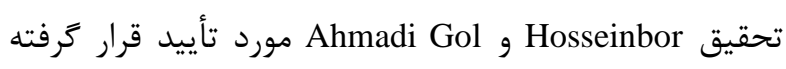

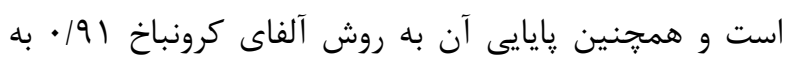

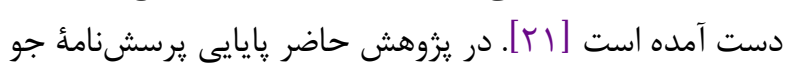

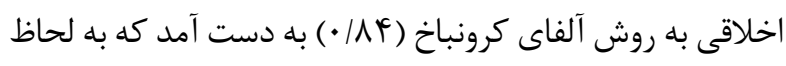

$$
\text { آمارى مورد قبول است. }
$$

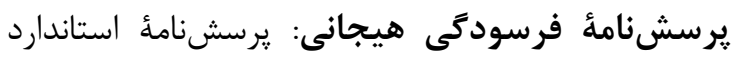

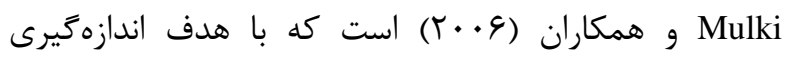

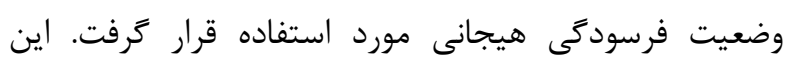

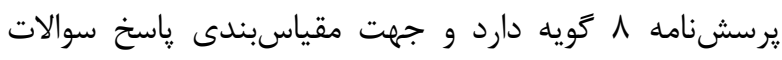


معنادارى ضرايب مسير مكمل بزرگى و جهت علامت ضريب آمائ

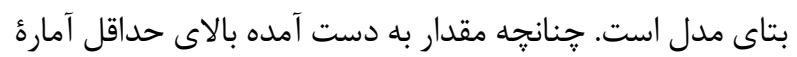

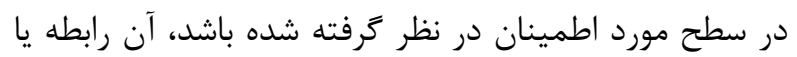

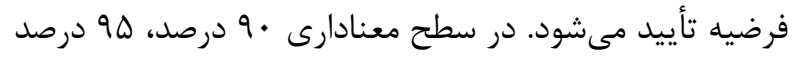

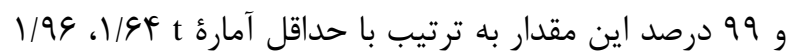

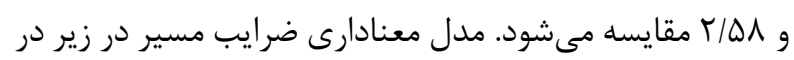
شكل r ارائه شده است.
نتايج شاخص ضريب تعيين در شكل ا نشان داده شده

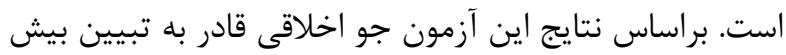
از Tr درصد از تغييرات فرسودىى هيجانى است. همجنين إنين

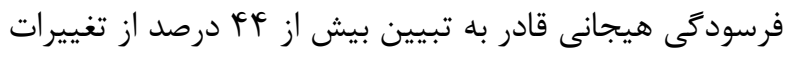

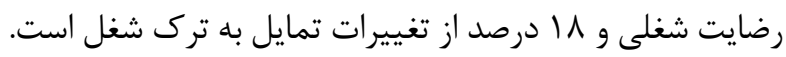
معنادارى ضرايب مسير (بتا): يكى از شاخصهاى تأييد

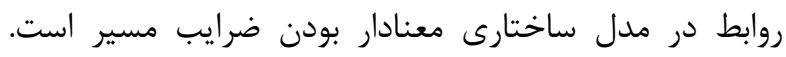
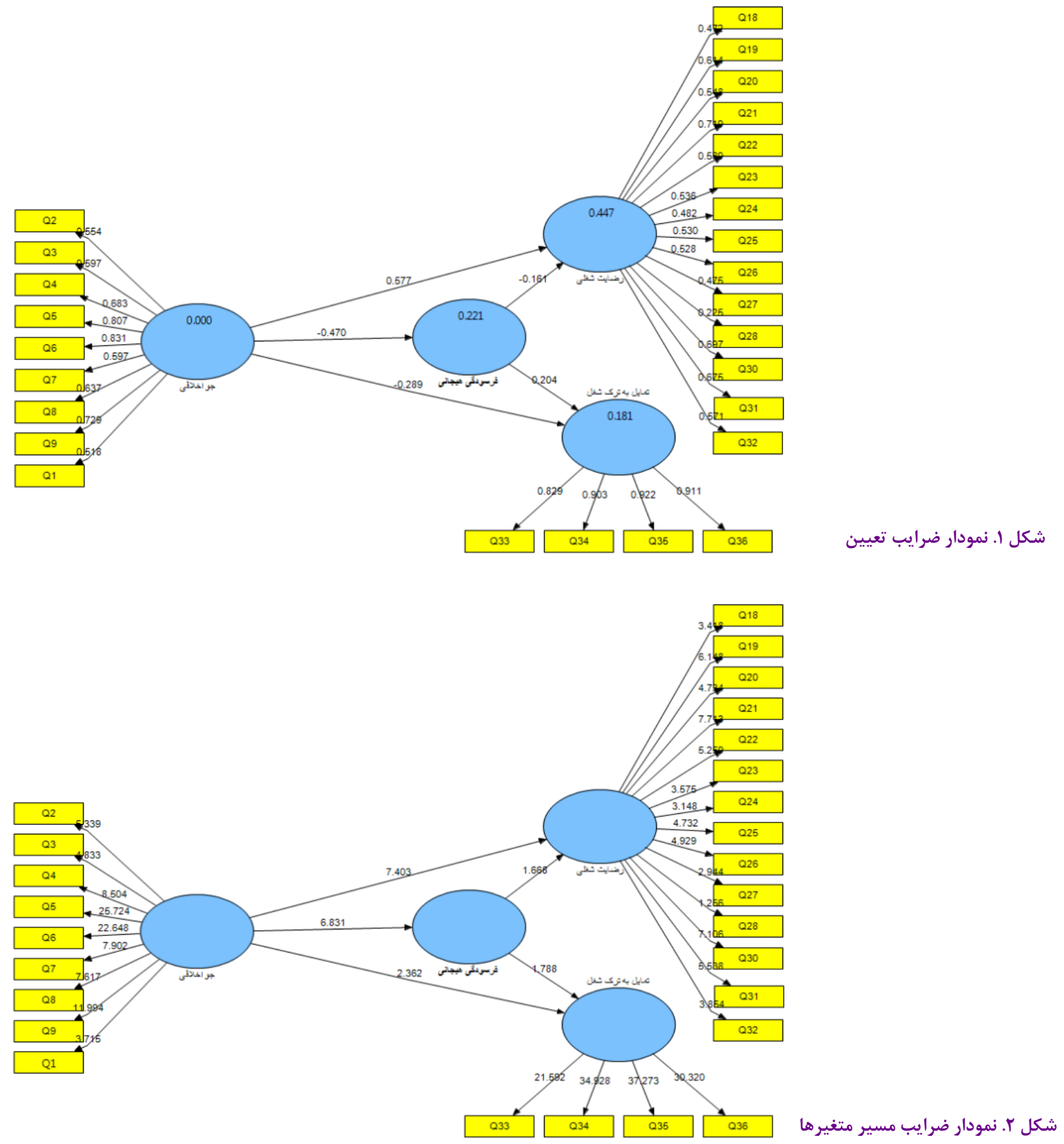


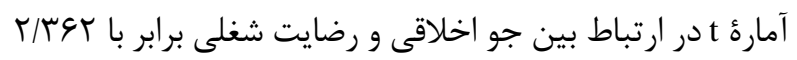

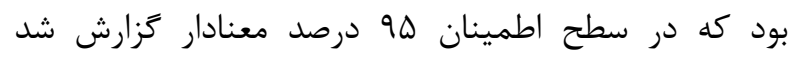

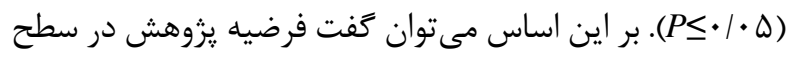
اطمينان له

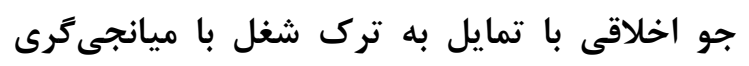
فرسودكى هيجانى در بين كاركنان ستادى شركت ناز آذربايجان غربى رابطه دارد.

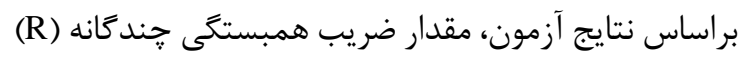

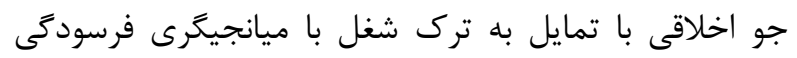

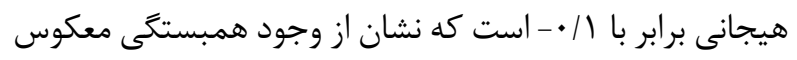

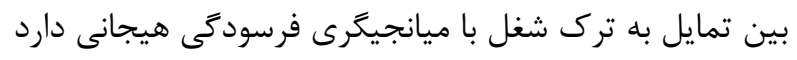

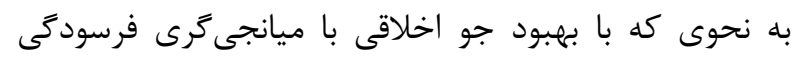

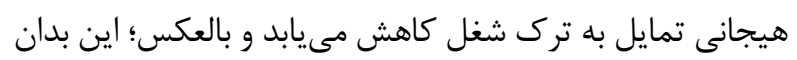

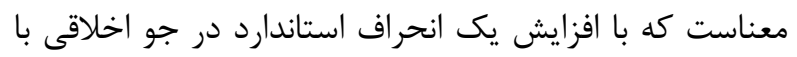

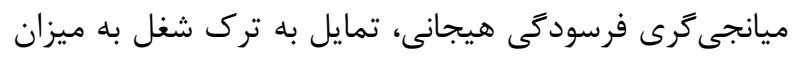

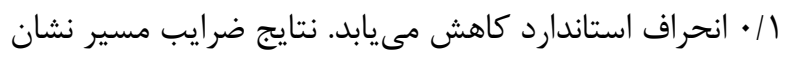

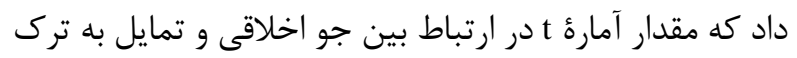

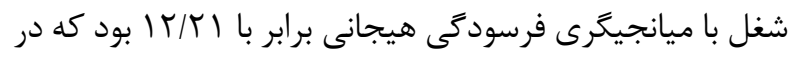

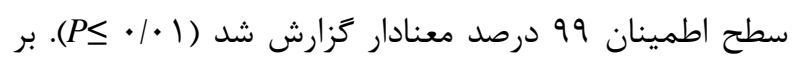
اين اساس مىتوان كفت فرضيه يزوهش در سطح اطمينان 99 درصد تأييد شد.

\section{فرسودىى هيجانى با رضايت شغلى در بين كاركنان}

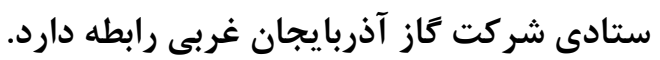

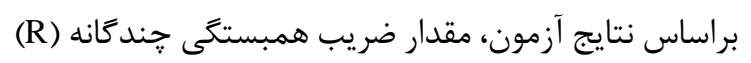

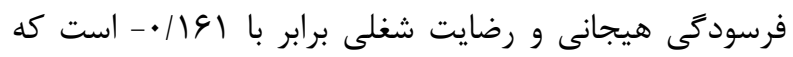

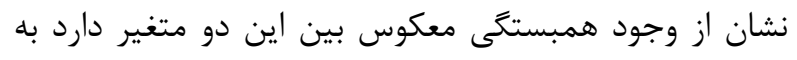

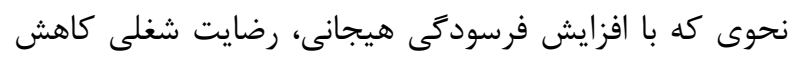

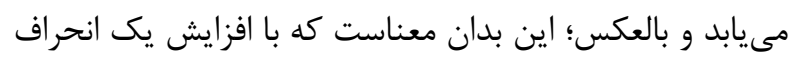

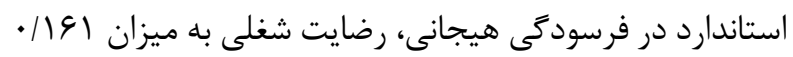

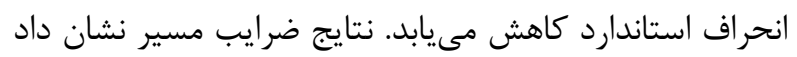

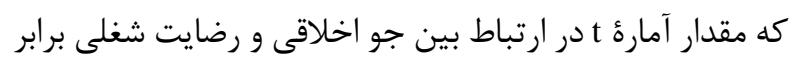

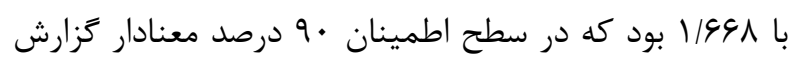

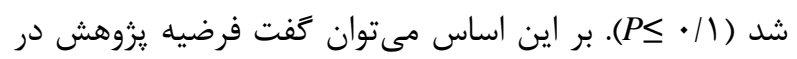
سطح اطمينان •9 درصد تأييد شد.

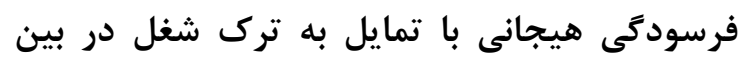

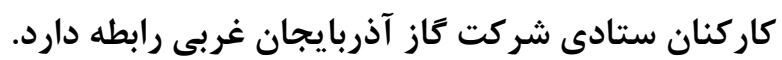

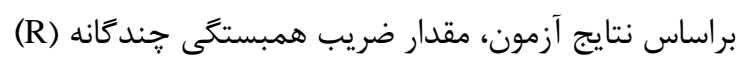

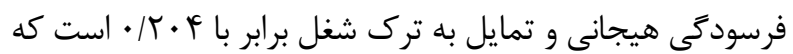

جو اخلاقى با رضايت شغلى در بين كاركنان ستادى

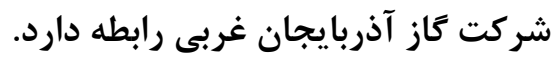

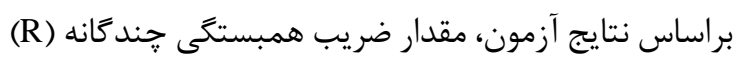

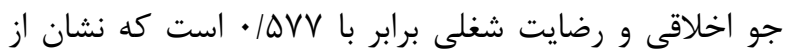

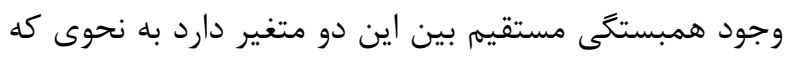

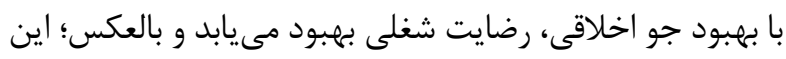
بدان معناست كه با افزايش يك انحراف استاندارد در جواني

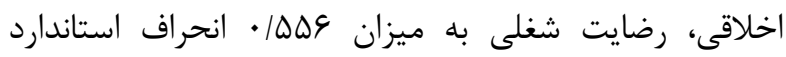

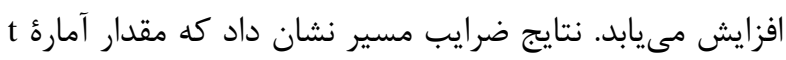

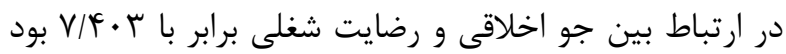
كه در سطح اطمينان 99 درصد معنادار كزارش شد (

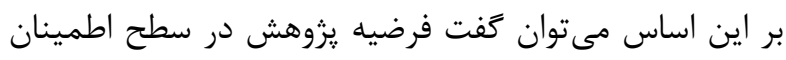
99 درصد تأييد شد (شكل م ؟).

جو اخلاقى با رضايت شغلى با ميانجيكرى فرسود هيجانى در بين كاركنان ستادى شركت كاز آذربائ غربى رابطه دارد.

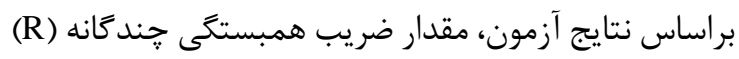

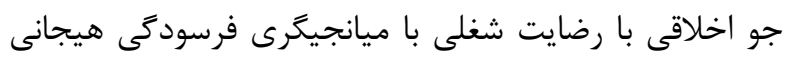

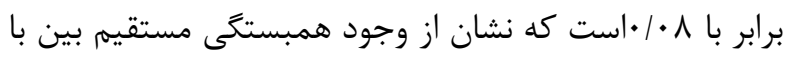

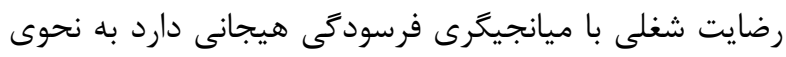

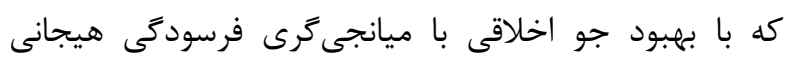

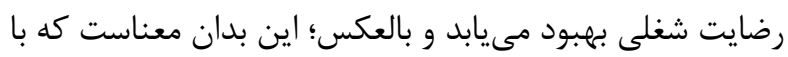

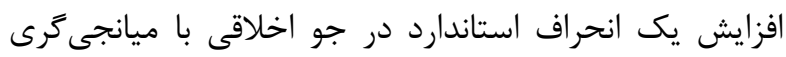

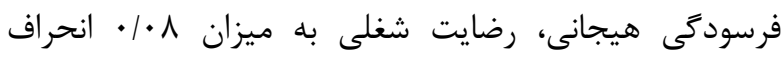

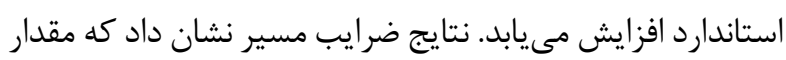

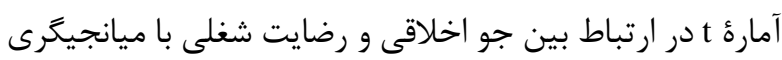

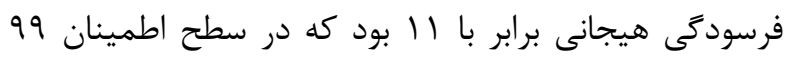

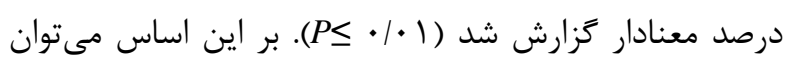

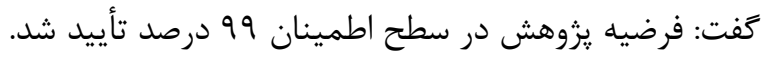

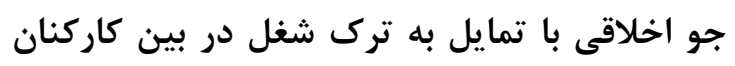
ستادى شركت كاز آذربايجان غربى رابطه دارد.

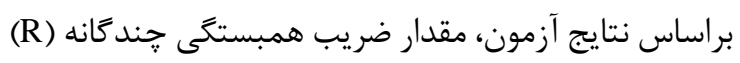

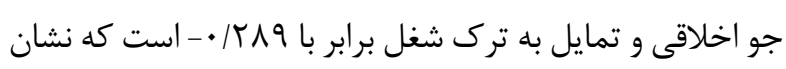

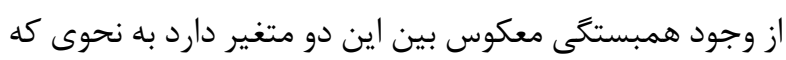

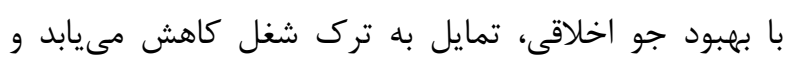

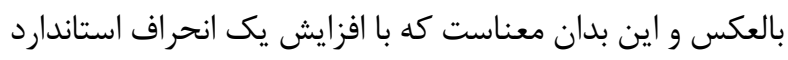

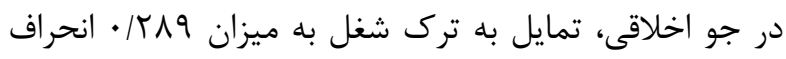

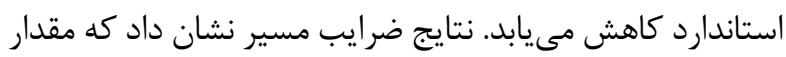




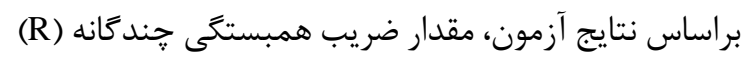

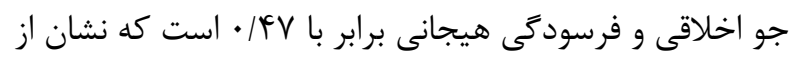

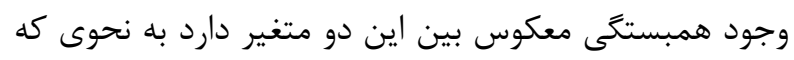

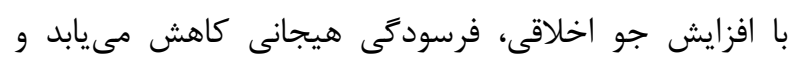

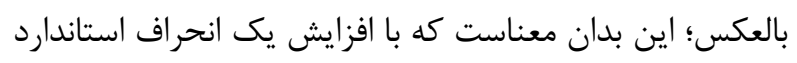

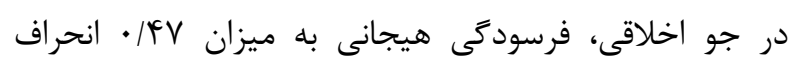

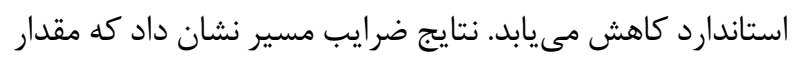

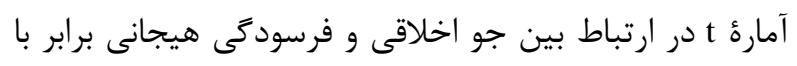

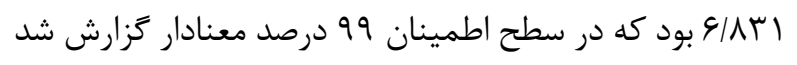

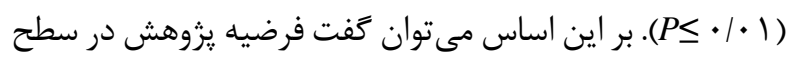
اطمينان 99 درصد تأييد شد. نتايج در شكل بان ارائه شده است.

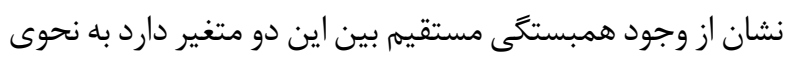

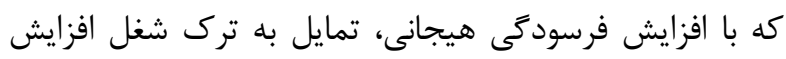

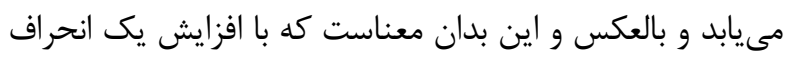

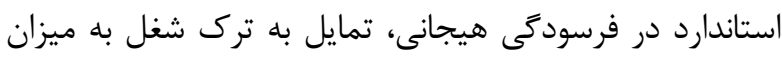

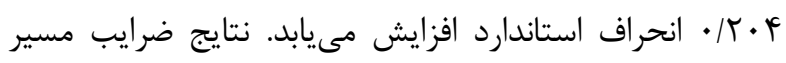

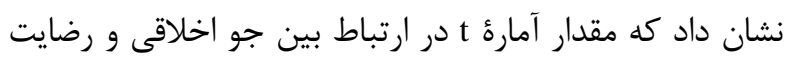

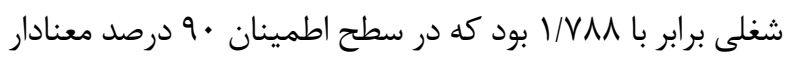

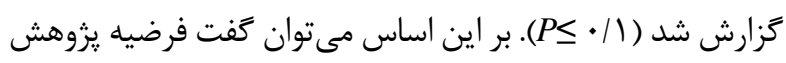

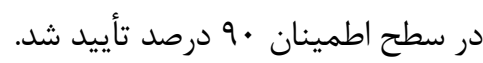

\section{جو اخلاقى با فرسودىى هيجانى در بين كاركنان} ستادى شركت گَاز اذربايجان غربى رابطه دارد.

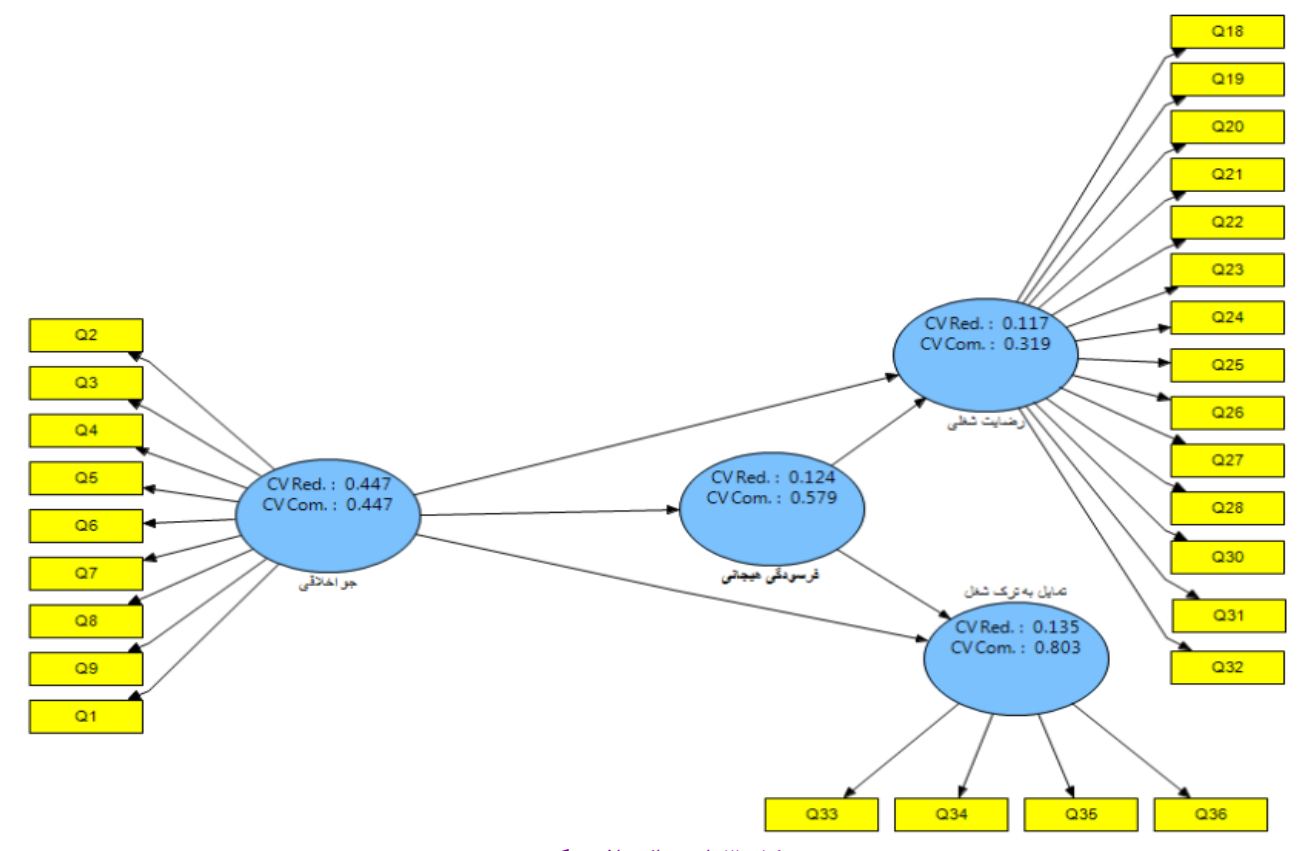

شكل r. اشتراك افزونكى

نمود. اين شاخص هر دو مدل ساختارى و اندازهيرى را به

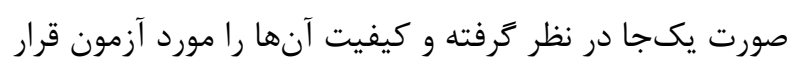

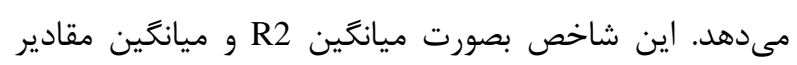
اشتراكى بصورت دستى محاسبه مىشود.

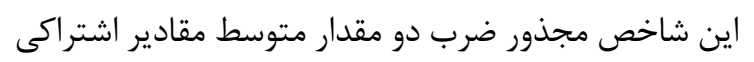

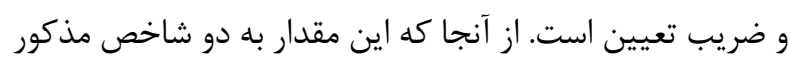

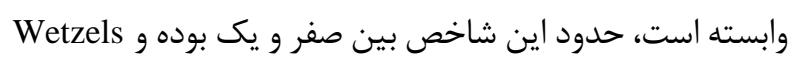

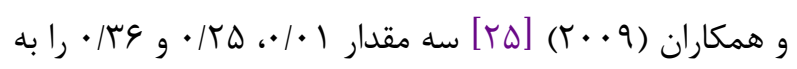
ترتيب به عنوان مقادير ضعيف؛ متوسط و قوى براى GOF

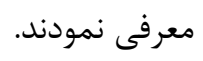

برازش كلى مدل معادلات ساختارى

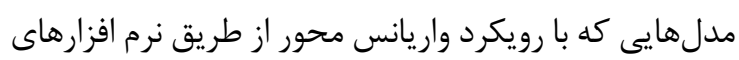

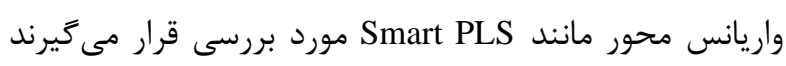

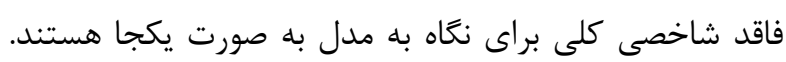

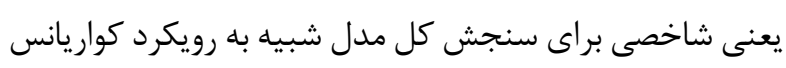

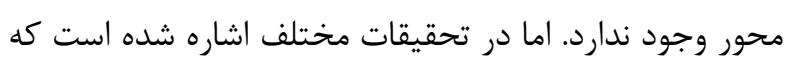

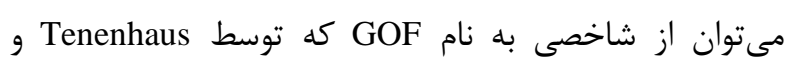

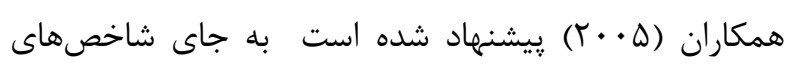
برازشى كه در رويكردهاى كواريانس محور وجود دارد، استفاده بـان 


\begin{tabular}{|c|c|c|c|c|c|}
\hline ضريب تعيين & ضريب تعيين & مقادير اشتراكى & مقادير اشتراكى & GOF & \\
\hline$\cdot|r T|$ & \multirow{4}{*}{$\cdot \mid \Delta r \cdot$} & $\cdot / \Delta N T$ & \multirow{4}{*}{./VYq } & \multirow{4}{*}{ •/rAV } & فرسودگى هيجانى \\
\hline- & & $\cdot \mid Y F V$ & & & جو اخلاقى \\
\hline - MFt & & $\cdot r \cdot r$ & & & رضايت شغلى \\
\hline$\cdot / 111$ & & $\cdot / V 9 \Delta$ & & & تمايل به ترك شغل \\
\hline
\end{tabular}

اين اساس مىتوان كَفت به نحوى كه با بهبود جو اخلاقى، تمايل

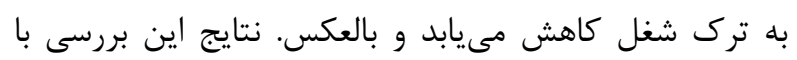

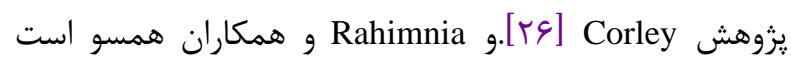
[rV]

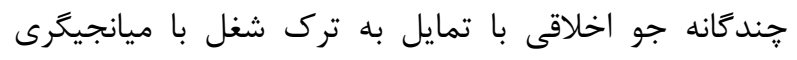

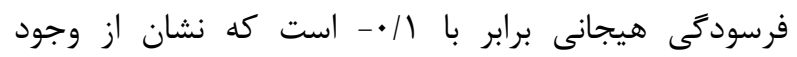

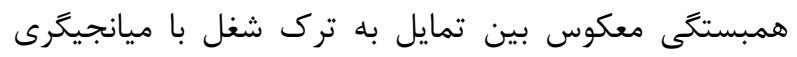

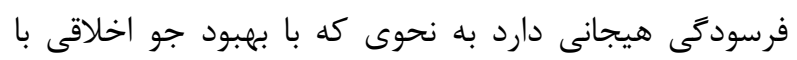

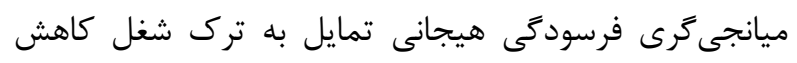

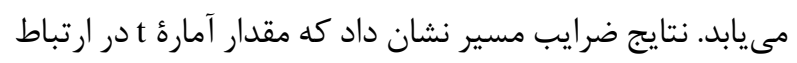

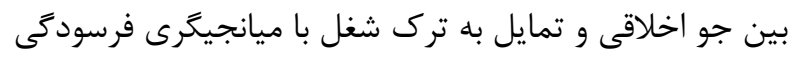

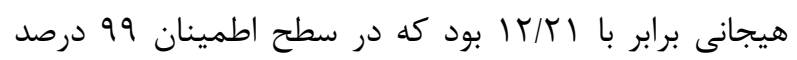

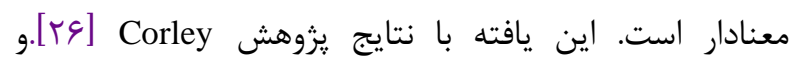
Rahimnia مقدار ضريب همبستكى جند

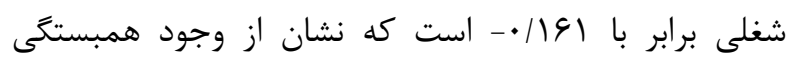

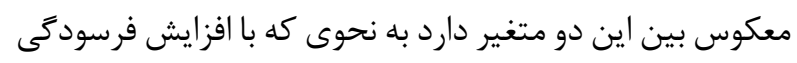

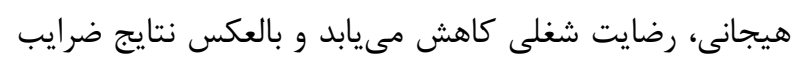

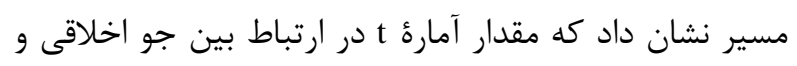

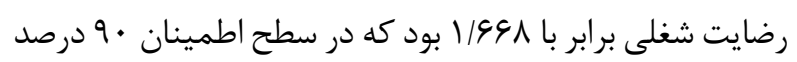

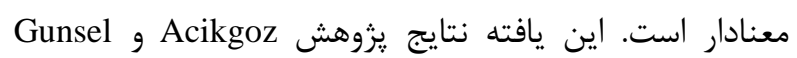

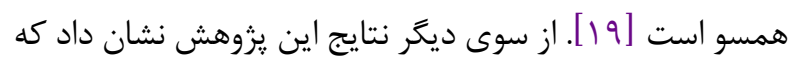

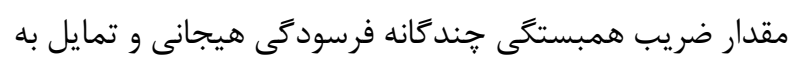

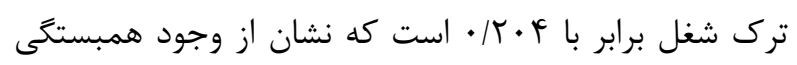

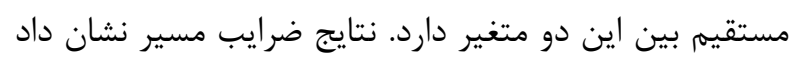

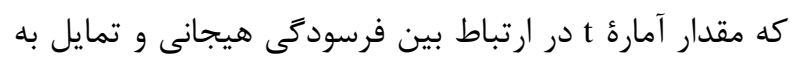

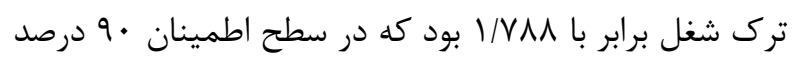

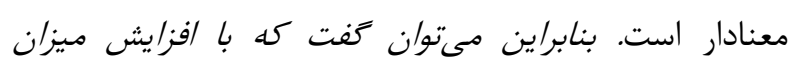

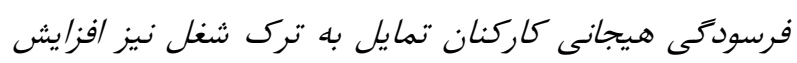

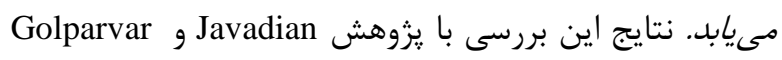

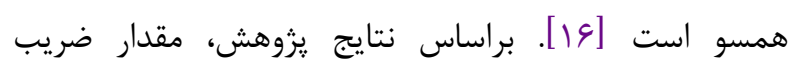

با توجه به مقدار به دست آمده براى GOF به ميزان ^/ •

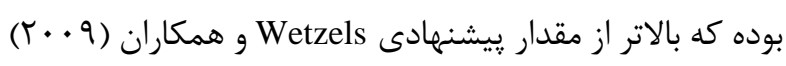

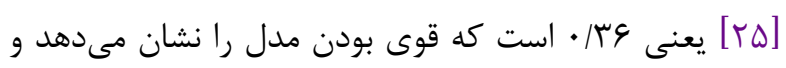
بنابراين برازش مناسب مدل كلى تأييد مىشون

\section{بحث}

يزروهش حاضر با هدف مدليابى ساختارى ارتباط جو

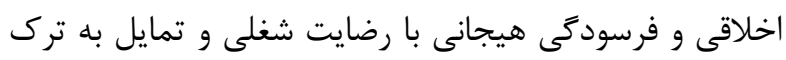

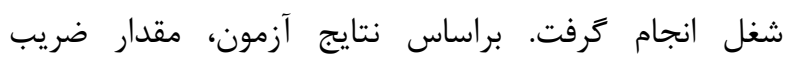

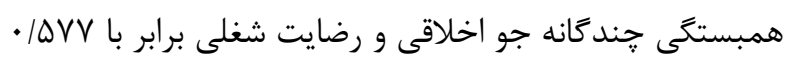

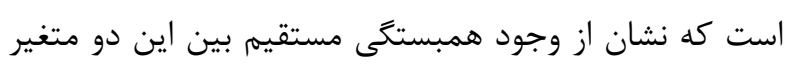

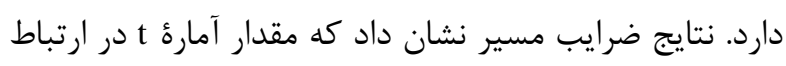

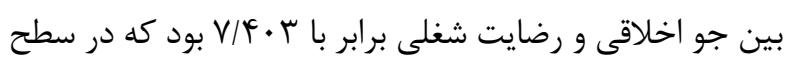

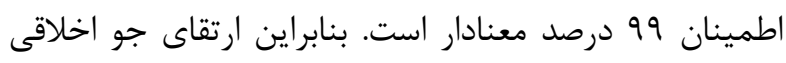

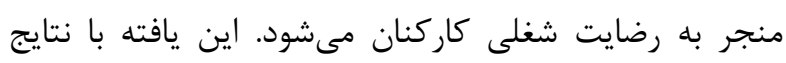

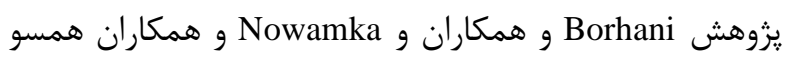

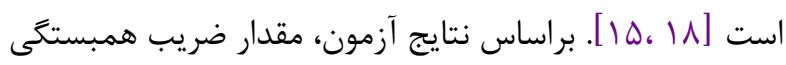

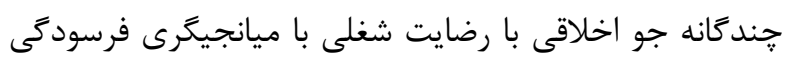

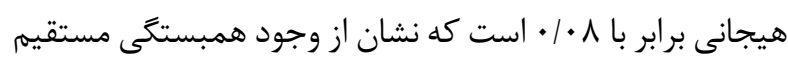

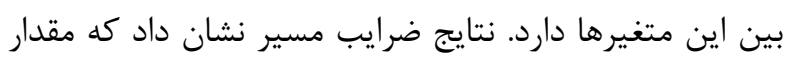

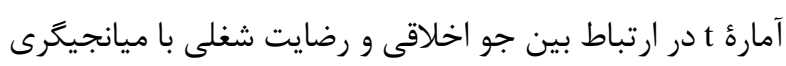

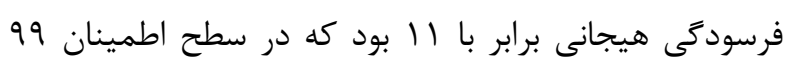

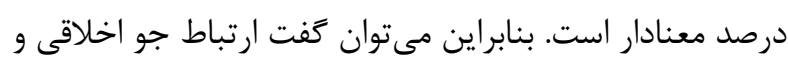

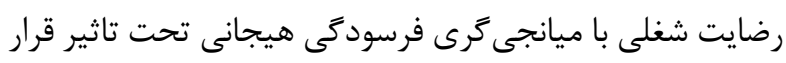

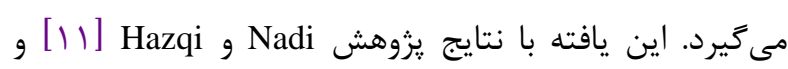
Nawamka

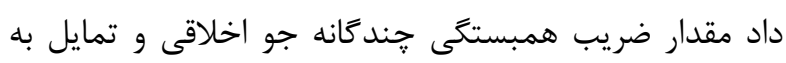

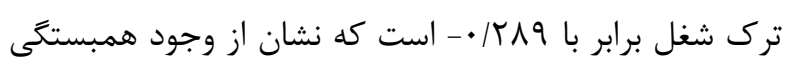

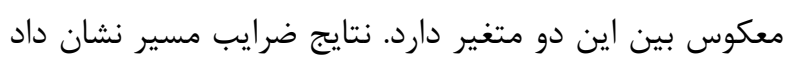

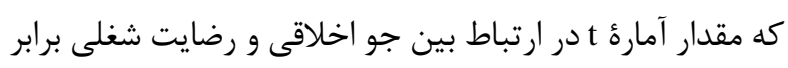

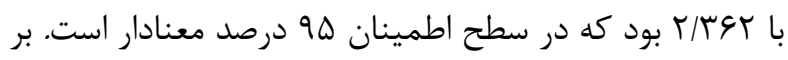


داشته شود. توجه به رشد اخلاقى كاركنان و بالا بردن سطح اخلاقى كاركنان با تدابيرى از قبيل آموزش آنان آنان در راستاى بردي

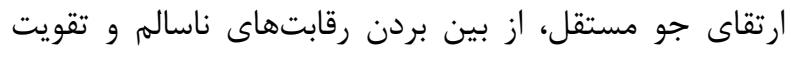

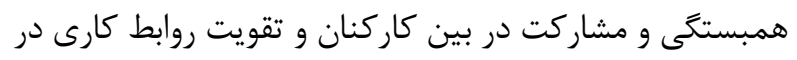

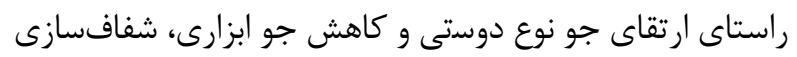

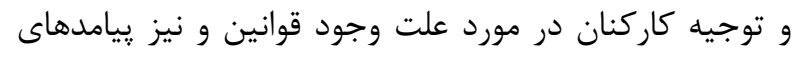

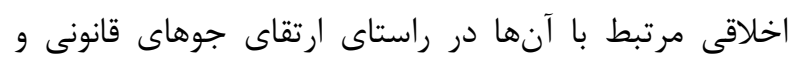

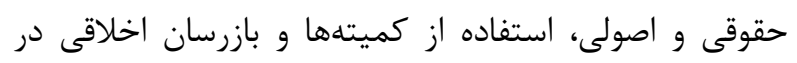

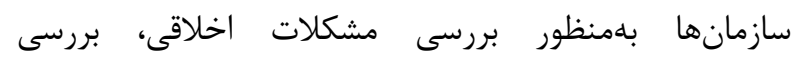

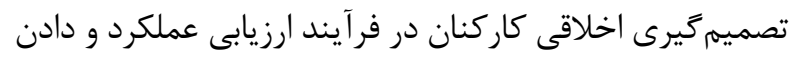

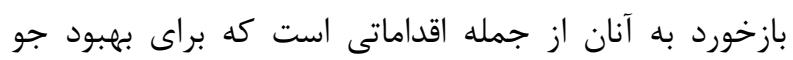

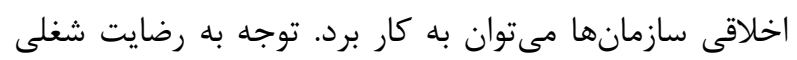

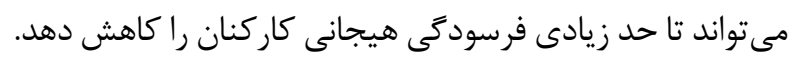

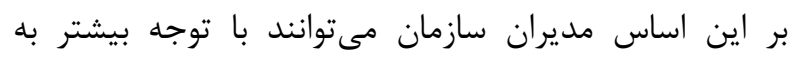
فاكتورهاى رضايت شغلى تا حد زيادى رضايت شغلى كار كنان

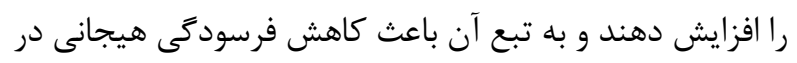

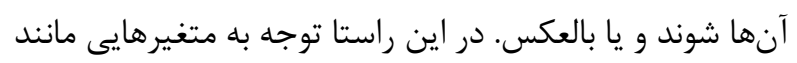

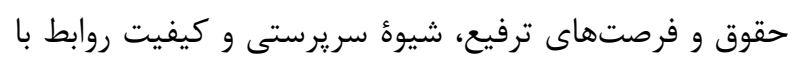

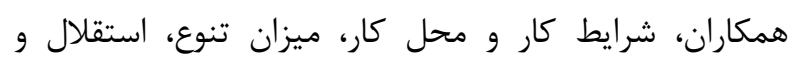
مسئوليت شغل و وضوح نقش بايد مورد توجه قرار كيرند. امروزه

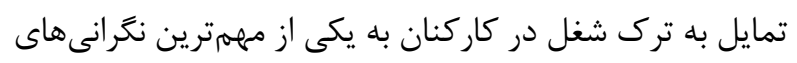

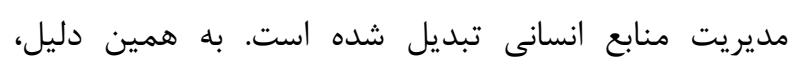

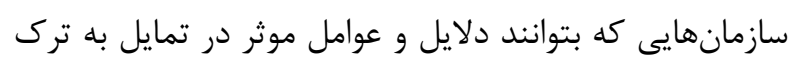

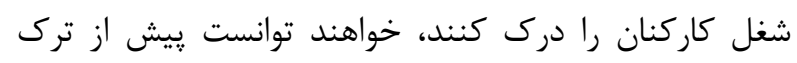

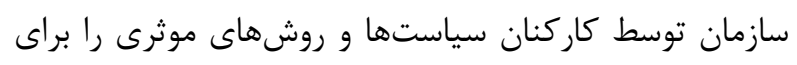

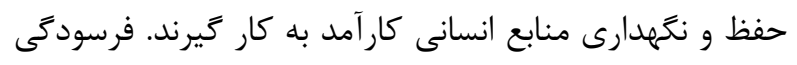

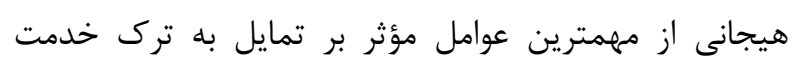

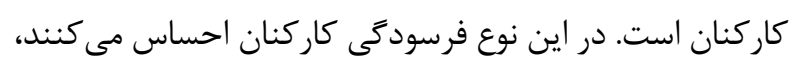

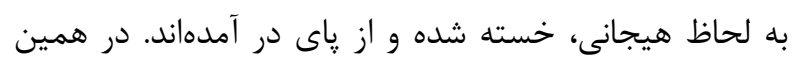

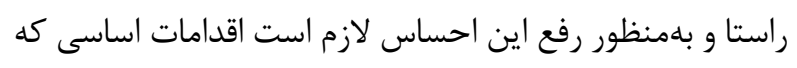

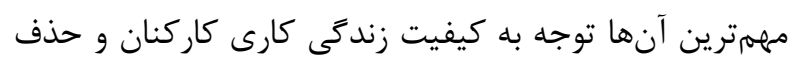

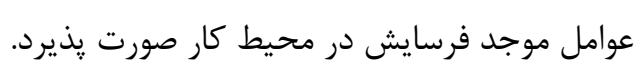

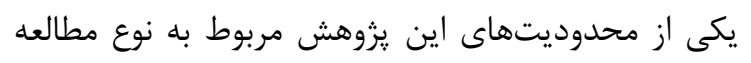

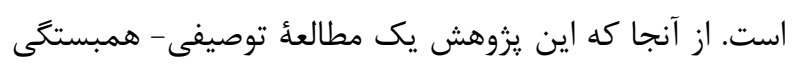

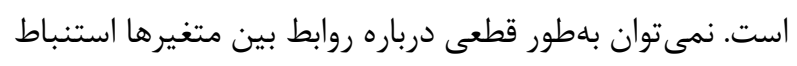

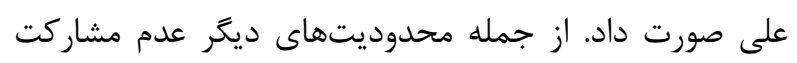
تعدادى از نمونه آمارى در يزوهش ارت جمله محدوديت استاي دي

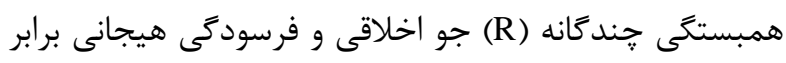

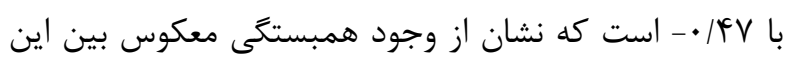

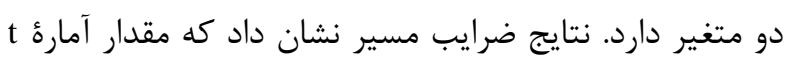

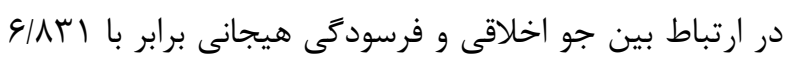

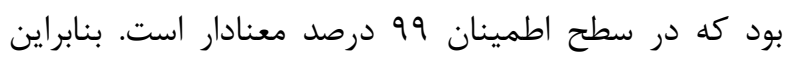

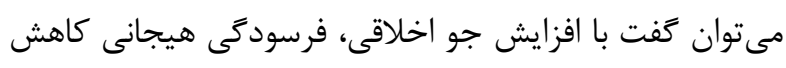

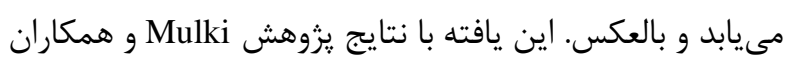

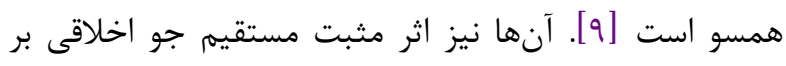
كاهش فرسودىى عاطفى كاركنان را تأييد كردند.

\section{نتيجه كَيرى}

براساس نتايج تحقيق توجه به جو اخلاقى و تلاش براى

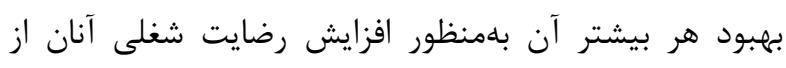
مواردى است كه هم كاركنان و همم مديران بايد به آن آن اهتمام

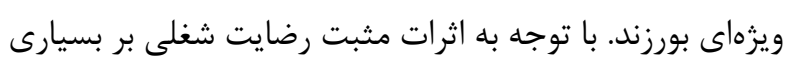

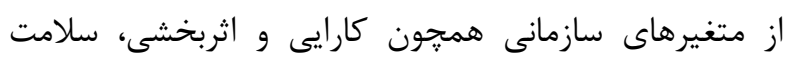

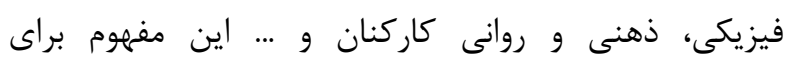

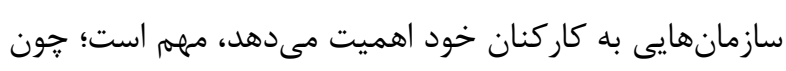

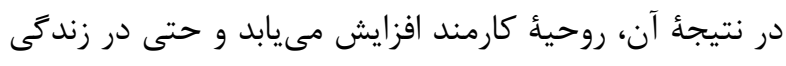

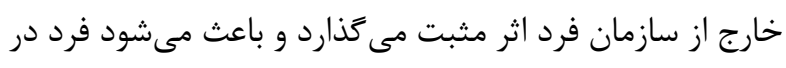

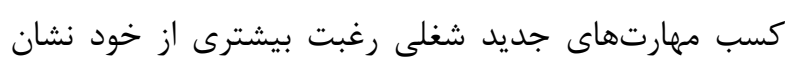

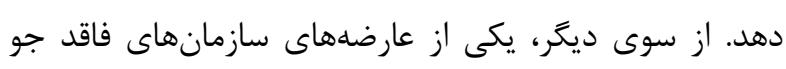

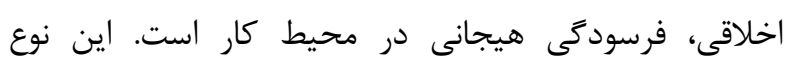

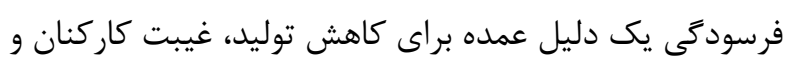

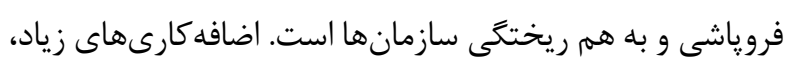

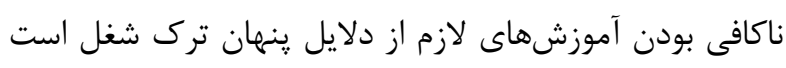

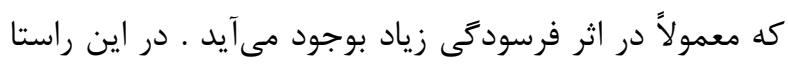

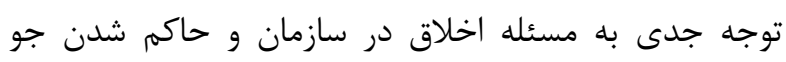

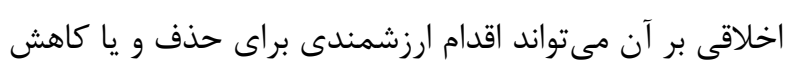

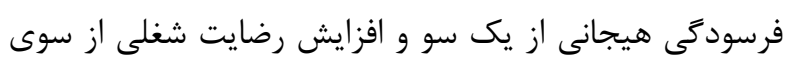

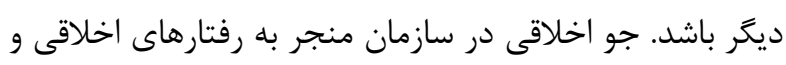

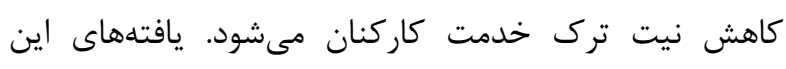

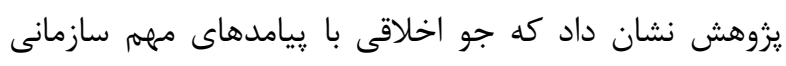

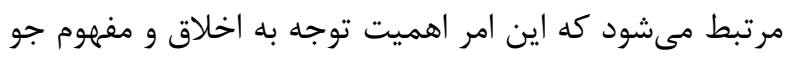

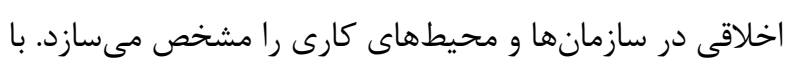

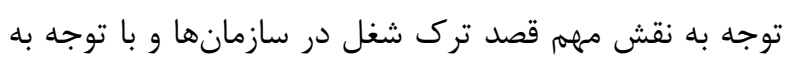

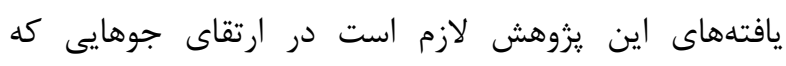

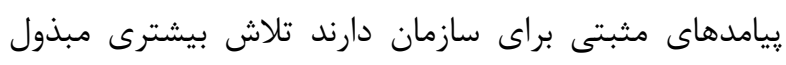




$$
\begin{aligned}
& \text { بين نويسند كان هينج گونه تعارضى در منافع وجود ندارد. } \\
& \text { منابع مالى } \\
& \text { منابع مالى اين مقاله توسط نويسندكان تهيه شده است. }
\end{aligned}
$$

\section{References}

1. Elci M, Alpkan L. The impact of perceived organizational ethical climate on work satisfaction. J Bus Ethic. 2009; 84:297-311. [DOI:10.1007/s10551008-9709-0]

2. Schwepker $\mathrm{CH}$. Ethical climate's relationship to job satisfaction, organizational commitment, and turnover intention in the salesforce. J Bus Res. 2001; 54(1):3952. [DOI:10.1016/S0148-2963(00)00125-9]

3. Webber SH. Ethical climte typology and questionnaire: A discussion of instument modifications. J Acad Lib. 2007; 33:567-80. [DOI:10.1016/j.acalib.2007.05.003]

4. Okpara O. John W. The impact Ethical climate on job satisfaction, and commitment in Nigeria. J Manag Dev. 2008; 9:54-63. [DOI:10.1108/02621710810901282]

5. Liu AM, Fellows R, Ng J. Surveyors' perspectives on ethics in organisational culture. Eng Cons Arch Manag. 2004; 11(6):438-49. [DOI:10.1108/09699980410570193]

6. Shapira-Lishchinsky O, Rosenblatt Z. School ethical climate and teachers' voluntary absence. J Edu Admin. 2010; 48(2):164-81. [DOI:10.1108/09578231011027833]

7. Martin KD, Cullen JB. Continuities and Extensions of Ethical Climate Theory: A Meta-Analytic Review. J Bus Ethic. 2006; 69(2):175-94. [DOI:10.1007/s10551006-9084-7]

8. Lewis PS, Goodman SH, Fandt PM, Michlitsch JF. Management: challenges for tomorrow's leaders. 4th ed. Florence (KY): Cengage Learning; 2003.

9. Mulki JP, Jaramillo JF, Locander WB. Effect of ethical climate on turnover intention: Linking attitudinal-and stress theory. J Bus Ethic. 2008 Apr;78(4):559-74. [DOI:10.1007/s10551-007-9368-6]

10. Cullen JB, Parboteeah KP, Victor B. The effects of ethical climates on organizational commitment: a twostudy analysis. J Bus Ethic. 2003; 46(2):27-47. [DOI:10.1023/A:1025089819456]

11. Nadi MA, Hazqi, F. Modeling the structural equation of the relationship between ethical climate, job satisfaction and organizational commitment with the intention of leaving the service among the staff of private hospitals in Shiraz. J Health Inf Manag. 2010; 8(5):699-708.

\author{
تقدير و تشكر

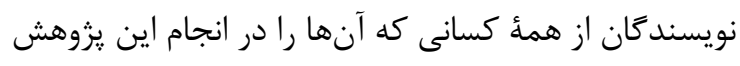

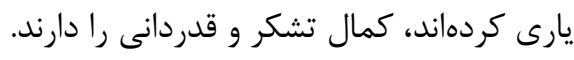 \\ تعارض منافع
}

12. Rasouli R, Shahai B, Safaei M. Factors affecting the intention to leave the service of employees in the central organization of Payame Noor University. J Pub Manag. 2012; 4(9):27-42.

13. Homan HA. Standardization of scale of job satisfaction. Tehran: Center training of republic administration; 2002.

14. Cortese CG. Job satisfaction of Italian nurses: an exploratory study. J Nurs Manag. 2007; 15(3):303-12. [DOI:10.1111/j.1365-2834.2007.00694.x] [PMID]

15. Borhani F, Atashzadeh Shurideh F, Pourhosseingholi MA, Maani S. Correlation between Ethical Atmosphere and Job Satisfaction of Nurses in Selected Hospitals of Shahid Beheshti University of Medical Sciences. J Med Ethics. 2015; 10(38):35-51. [DOI:10.21859/mej103851]

16. Javadian Z, Golparvar M. The Relationship between Job Stress and Dismissal and Deviant Behaviors Due to the Modifying Role of Psychosocial Needs. Dev Manag Quart. 2015; 28(1):51-68.

17. Nikbakht Nasrabadi A, Salari A, Hosseinpour M, Yekaninejad M. Study the rate of burnout and intention to leave and their relationship among emergency department nurses. IJNR. 2014; 9(3):19-29.

18. Novamka E. Ethical atmosphere and job satisfaction among organizational buyers. J Bus Ethic. 2008; 78(4):25-38.

19. Acikgoz A, Gunsel A. The effects of organizational climate on team innovativeness. Proc Soc Behav Sci. 2011; 24(1):920-7. [DOI:10.1016/i.sbspro.2011.09.102]

20. Davardi A, Reza Zadeh A. Structural Equations Using Smart PLS, First Edition. Tehran: Sociologists Publications; 2013.

21. Hosseinbor MO, Ahmadi Gol M. Investigating the Relationship between Ethical Climate and Organizational Knowledge Creation. Pub Manag Res. 2017; 10(35):183-208.

22. Golparvar M, Aghaei A. Hoseinzadeh K. The Structural Model of the Relationships of Person-Job Fit, with Emotional Exhaustion and Job Attitudes. Know Res Appl Psych. 2013; 14(1):23-33.

23. Taghipour M, Mohammadi M, Savar Rakhsh M, Heidari R. The Relationship between Job Satisfaction and Manpower Productivity in an Industrial Unit. Paper 
presented at The First International Conference on Industrial Engineering, Management and Accounting. Tehran, Iran; 2015.

24. Golparvar M, Hoseinzadeh K. Model of relation between person-job none fit with emotional exhaustion and desire to leave work: Evidence for the stress unequilibrium-compensation model. J Appl Psych. 2014; 1(17):41-56.

25. Wetzels M, Odekerken-Schröder G, Van Oppen C. Using PLS path modeling for assessing hierarchical construct models: Guidelines and empirical illustration. MIS quarterly. 2009:177-95. [DOI:10.2307/20650284]

26. Corley MC. Moral distress of critical care nurses. Am J Crit Care 1995; 4(4): 280-5. [DOI:10.4037/ajcc1995.4.4.280] [PMID]

27. Rahimnia F, Nikkhah Farkhani Z. The effects of ethical climate on organizational identity and turnover Intentions among salespeople. J Eth Sci Technol. 2012; 6 (4) :85-95. 